\title{
UCRL-TR-233539
}

LAW RENCE LIVERMORE N A TIO NAL LABORATORY
Berkeley Seismological Laboratory Seismic Moment Tensor Report for the August 6, 2007 M3.9 Seismic event in central Utah

Sean Ford, Doug Dreger, Peggy Hellweg

August 9, 2007 
This document was prepared as an account of work sponsored by an agency of the United States government. Neither the United States government nor Lawrence Livermore National Security, LLC, nor any of their employees makes any warranty, expressed or implied, or assumes any legal liability or responsibility for the accuracy, completeness, or usefulness of any information, apparatus, product, or process disclosed, or represents that its use would not infringe privately owned rights. Reference herein to any specific commercial product, process, or service by trade name, trademark, manufacturer, or otherwise does not necessarily constitute or imply its endorsement, recommendation, or favoring by the United States government or Lawrence Livermore National Security, LLC. The views and opinions of authors expressed herein do not necessarily state or reflect those of the United States government or Lawrence Livermore National Security, LLC, and shall not be used for advertising or product endorsement purposes.

This work performed under the auspices of the U.S. Department of Energy by Lawrence Livermore National Laboratory under Contract DE-AC52-07NA27344. 


\title{
UCRL-TR-233539
}

\section{Berkeley Seismological Laboratory Seismic Moment Tensor Report for the August 6, 2007 M3.9 Seismic event in central Utah}

\author{
Prepared by Sean Ford ${ }^{1,2}$, Douglas Dreger ${ }^{1}$, and Peggy Hellweg ${ }^{1}$ \\ 1. Berkeley Seismological Laboratory \\ 2. Summer Intern at the Lawrence Livermore National Laboratory
}

\section{Last Updated: August 8, 2007}

We have performed a complete moment tensor analysis of the seismic event, which occurred on Monday August 6, 2007 at 08:48:40 UTC 21 km from Mt.Pleasant, Utah. In our analysis we utilized complete three-component seismic records recorded by the USArray, University of Utah, and EarthScope seismic arrays. The seismic waveform data was integrated to displacement and filtered between 0.02 to $0.10 \mathrm{~Hz}$ following instrument removal. We used the Song et al. (1996) velocity model to compute Green's functions used in the moment tensor inversion. A map of the stations we used and the location of the event is shown in Figure 1.

In our moment tensor analysis we assumed a shallow source depth of $1 \mathrm{~km}$ consistent with the shallow depth reported for this event. As shown in Figure 2 the results point to a source mechanism with negligible double-couple radiation and is composed of dominant CLVD and implosive isotropic components. The total scalar seismic moment is 2.12e22 dyne $\mathrm{cm}$ corresponding to a moment magnitude $(\mathrm{Mw})$ of 4.2 . The long-period records are very well matched by the model (Figure 2 ) with a variance reduction of $73.4 \%$. An all dilational (down) first motion radiation pattern is predicted by the moment tensor solution, and observations of first motions are in agreement. 
UCRL-TR-233539

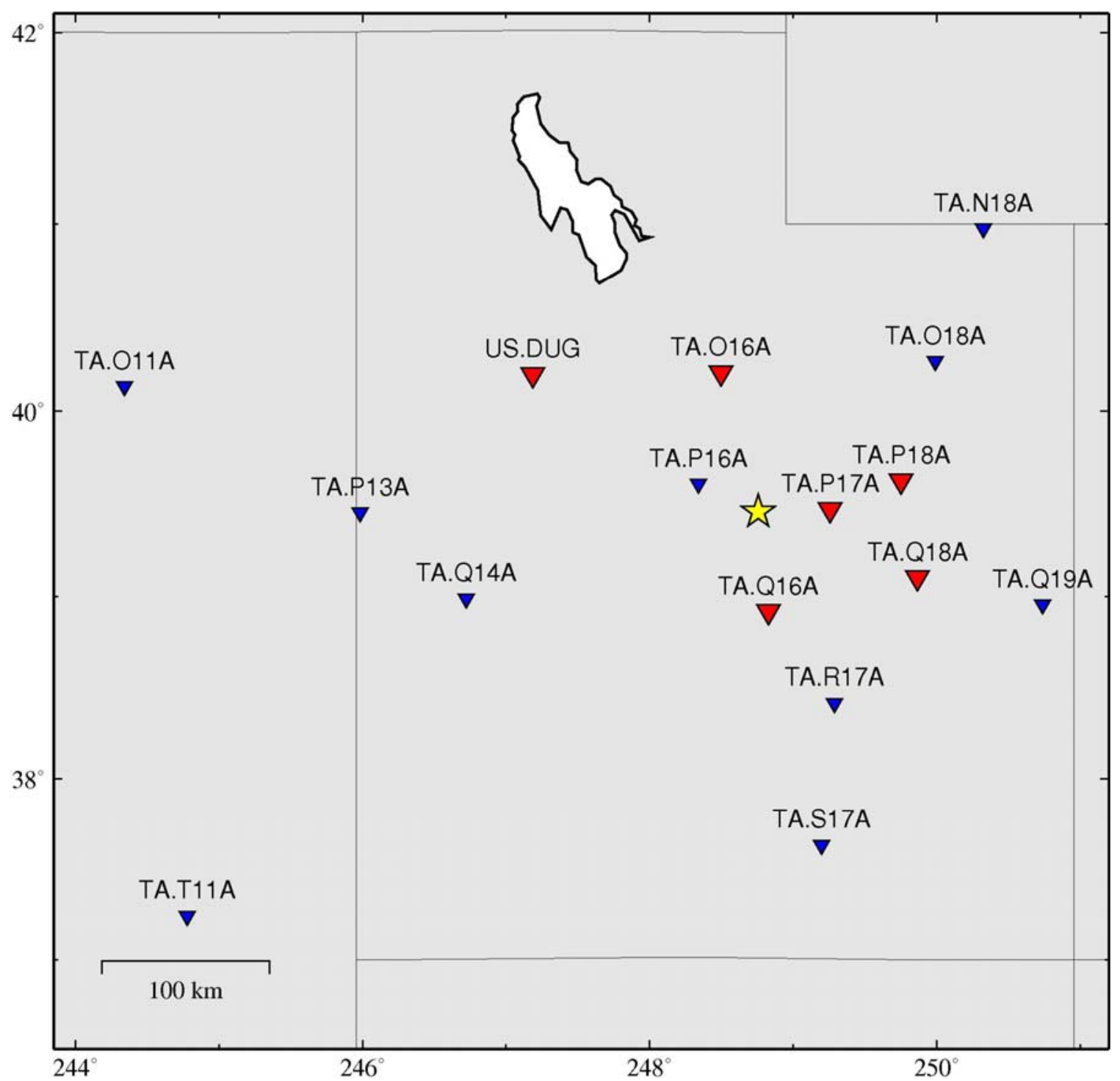

Figure 1. Map showing event location (yellow star) and stations used (triangles). The red triangles show the near stations that we show in Figure 2, and the blue triangles show the stations used in Figure 3. 


\section{UCRL-TR-233539}

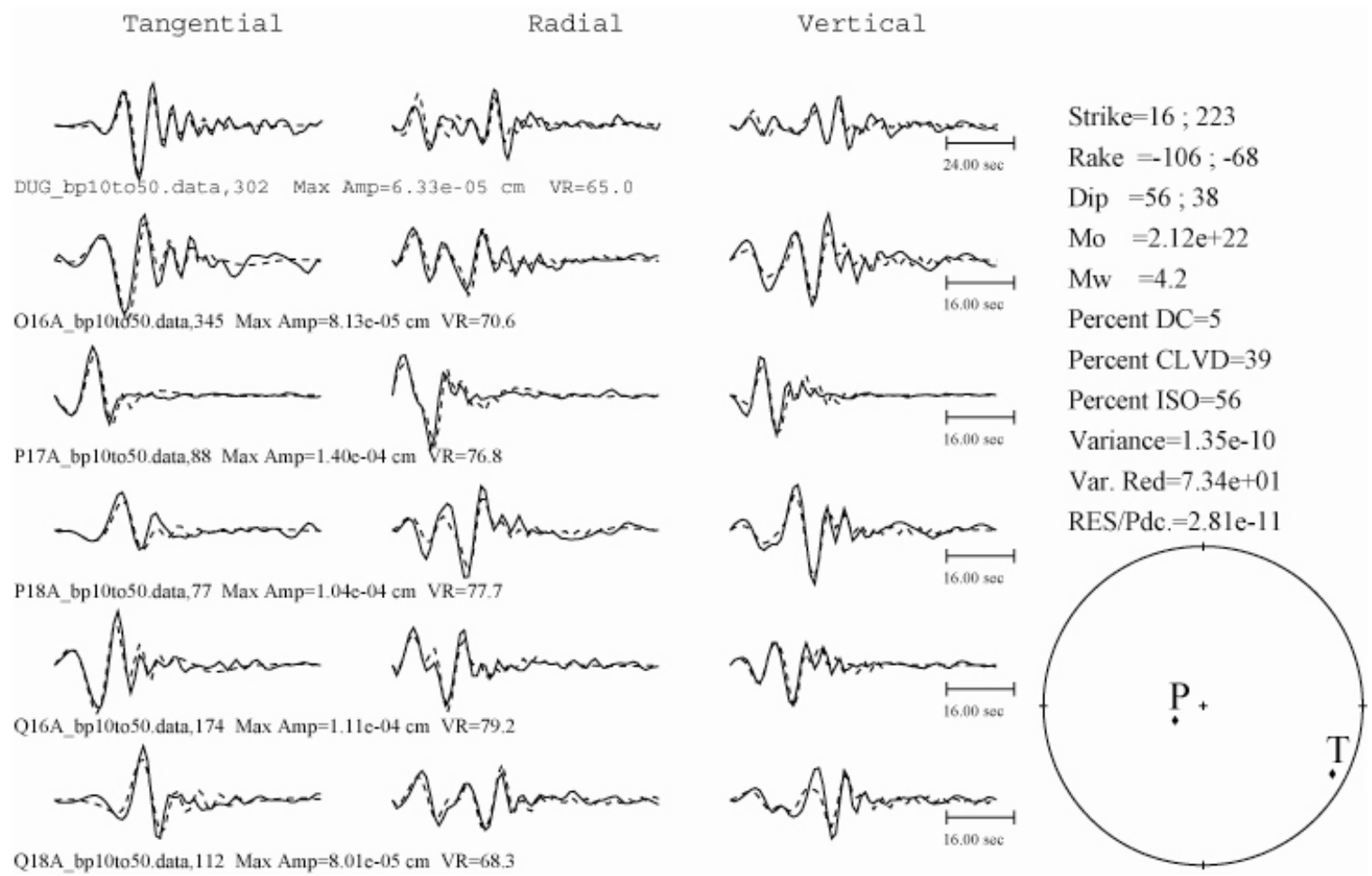

Figure 2. Moment tensor solution using six regional stations. The observations are solid lines and the synthetic seismograms are dashed. The $\mathrm{P}$ wave radiation pattern is plotted together with the orientation of the compressive axis.

The results in Figure 1 using 6 close stations is the same as the result we obtained using 16 stations (Figure 3). We also performed a deviatoric moment tensor inversion in which volumetric source are disallowed. The results of this inversion (Figure 4) indicated much poorer fit (only a $41.8 \%$ variance reduction), and a $\mathrm{P}$-wave first motion radiation pattern that is inconsistent with the observed first motions. 


\section{UCRL-TR-233539}

Tangential

Radial

Vertical

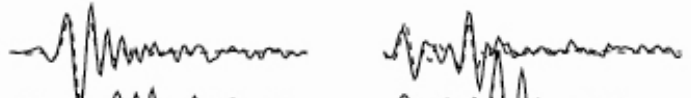

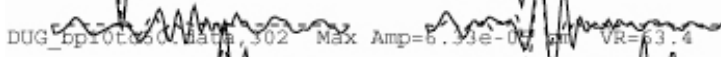

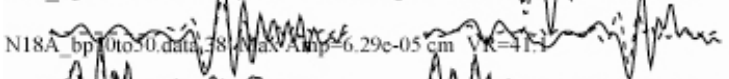

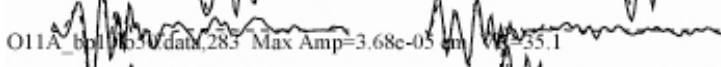

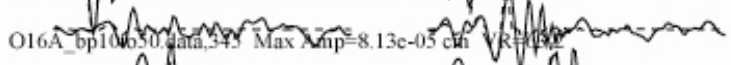

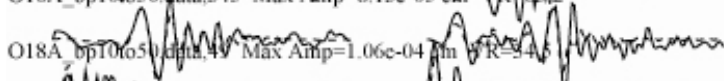

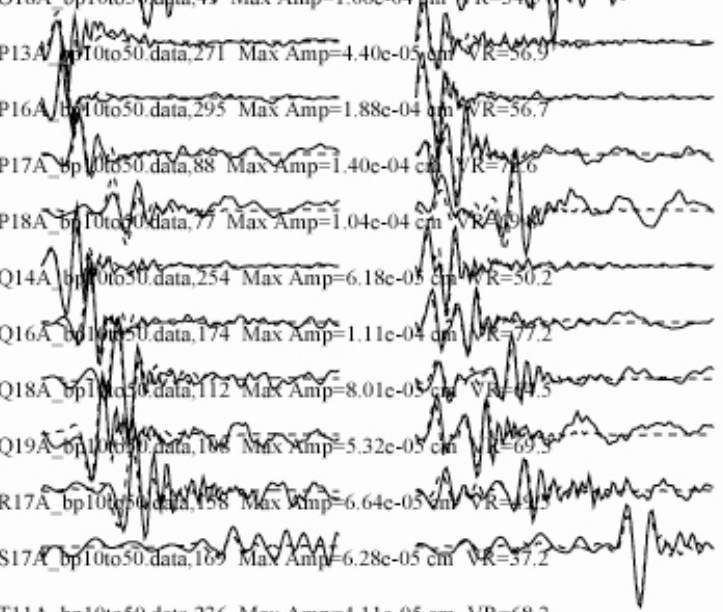

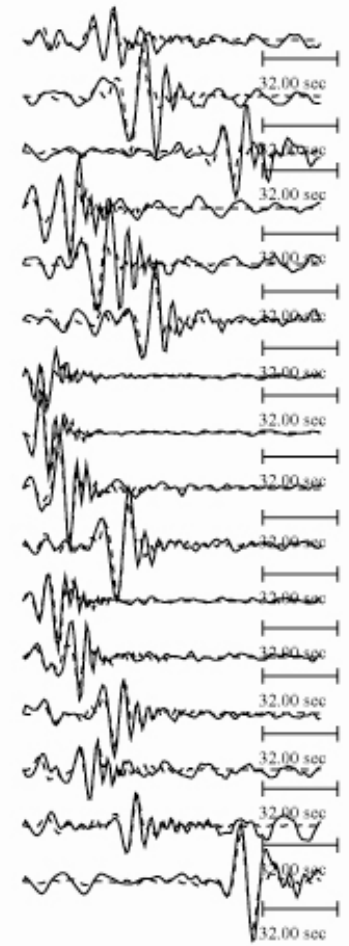

Strike $=25 ; 233$

Rake $=-109 ;-69$

Dip $=50 ; 44$

Mo $=1.91 \mathrm{e}+22$

$\mathrm{Mw}=4.2$

Percent DC $=6$

Percent $\mathrm{CLVD}=37$

Percent $\mathrm{ISO}=57$

Variance $=1.05 \mathrm{e}-10$

Var. Red $=5.41 \mathrm{e}+01$

$\mathrm{RES} / \mathrm{Pdc} .=1.80 \mathrm{e}-11$

Figure 3. Same as Figure 2 for the inversion utilizing 16 regional distance stations.

Tangential

Radial

Vertical

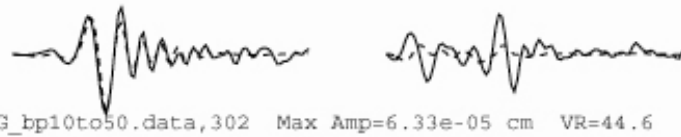

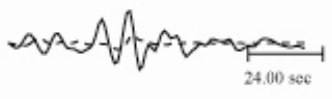

Strike $=154 ; 297$

Rake $=97 ; 54$

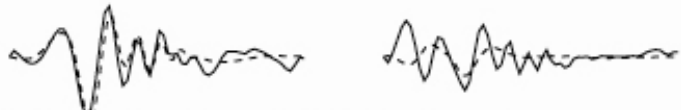

O16A_bp 10t850.data,345 Max Amp=8.13e-05 cm VR=35.5
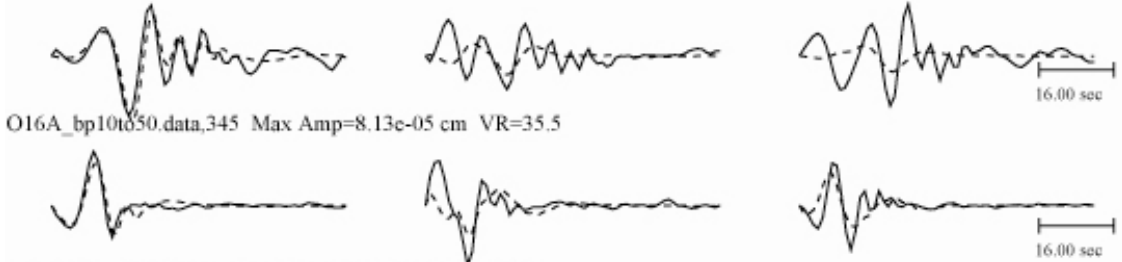

Dip $=80 ; 12$

Mo $=4.45 \mathrm{e}+21$

$\mathrm{Mw}=3.7$

Percent $\mathrm{DC}=99$

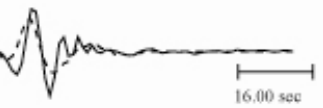

Percent CLVD=1

P17A bp10to50.data,88 Max Amp=1.40c-04 cm $/ \mathrm{R}=50.9$

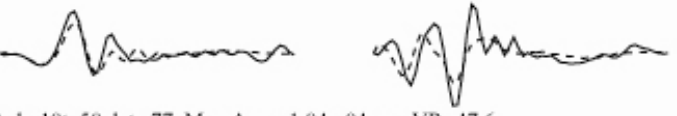

P18A bp10to50.data, 77 Max Amp=1.04e-(04 cm VR=47.6

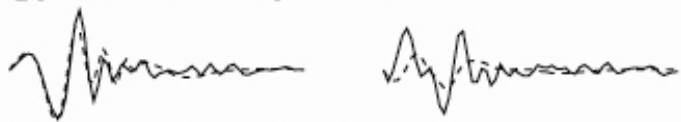

Q16A_bp 10to50,data,174 Max Amp=1.11e-04 cm VR=46,0
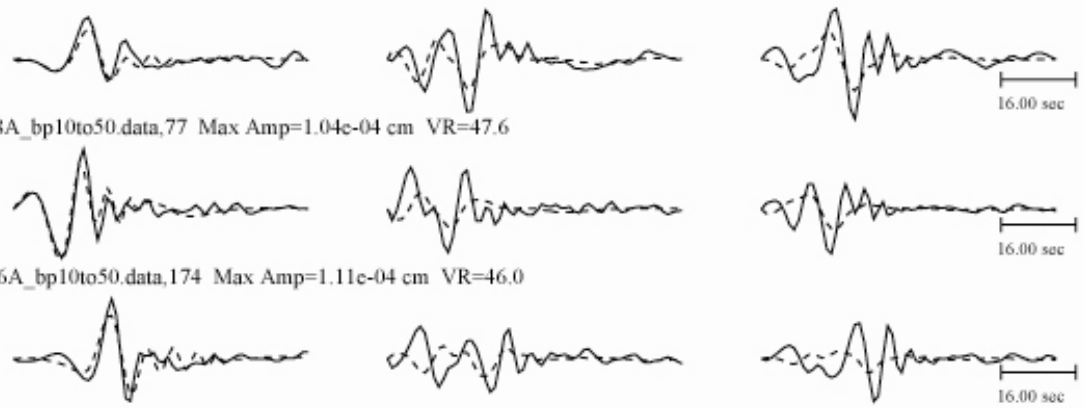

Percent $\mathrm{ISO}=0$

Variance $=3.03 \mathrm{e}-10$

Var. $\mathrm{Red}=4.18 \mathrm{e}+01$

$\mathrm{RES} / \mathrm{Pdc}=3.06 \mathrm{e}-12$

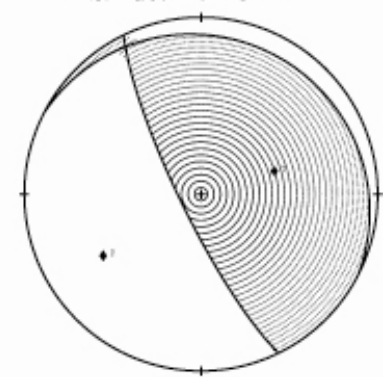

Q18A bp 10to50.data,112 Max Amp=8.01e-05 cm VR=19.6

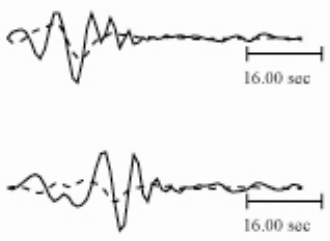

Figure 4. Deviatoric moment tensor solution using the same stations in Figure 2. Note that the fit of the data is significantly worse than in Figure 2. 


\section{UCRL-TR-233539}

The obtained source mechanism is consistent with the collapse of an underground cavity.

\section{Background on Moment Tensor Solutions}

The seismic moment tensor is able to describe tectonic earthquakes or double-couples (DC), and a variety of non-double-couple (non-DC) seismic events associated with geothermal, volcanic and human-induced causes. These non-DC events including isotropic events that can model changes in source volume in the elastic medium that might result from man-made explosions or natural processes in geothermal and volcanic environments. It can also describe the opening or closing of planar cracks in the Earth. The solution obtained above is consistent with the closure of a roughly horizontal crack. Figure 5 compares the basic types of seismic sources.

\section{Acknowledgements}

We would like to acknowledge Ralph Falk for assistance with our P-wave first motion analysis. 